\title{
George Lau \\ An Archaeology of Ancash: Stones, Ruins and Communities in Andean Peru
}

\author{
Routledge. London and New York, 2016, 257 p. (77 figuras)
}

"An Archaeology of Ancash" está dividida en nueve capítulos y cada uno de ellos toca un tema en particular pero que se entrelazan directamente. Lo primero que nos llama la atención es el orden en que se presentan los temas (la materialidad cambiante de la piedra y su rol) a lo largo del libro, por ejemplo, los capítulos 3, 4, 5 y 7 contemplan una presentación cronológica de periodos arqueológicos (desde los inicios de la arquitectura publica monumental hasta la presencia del Imperio inca) en Ancash. Mientras que los capítulos 6 y 8 apuntan más sobre temas teóricos de los convenios sociales (pasados y actuales) con la piedra. Esta obra cuenta con 16 páginas de fotografías en buena calidad de materiales y sitios arqueológicos, así como un glosario y un apéndice de apoyo, terminando con una de las más largas y comprensibles bibliografías sobre estudios publicados en la región. Vale decir que el lenguaje que maneja el libro no llega a lo técnico y es de fácil entendimiento, pero creemos que va dirigido a un público no especializado y/o que no tiene mayor referencia sobre los Andes Centrales.

Desde la introducción, el autor explica el porqué de la elección de la piedra como enfoque de estudio en base a su experiencia profesional y las razones que se dieron para que este material haya sido relevante a través de los años en los Andes Centrales, incluso llegando a tiempos republicanos. En ese sentido, uno de los motivos principales de Lau es el siguiente:

I have focused especially on the material qualities and forms of stone, in which reside cultural meanings. ${ }^{1}$ (pág. 214)

"Mehe centrado especialmente en las cualidades materiales y formas de la piedra,enlasqueresidensignificadosculturales.” (latraducciónesnuestra).
En otras palabras, escoge la piedra debido a la materialidad que representa. Ya sea como elemento para construir edificaciones, por su uso como herramienta, para su uso como elemento de adoración (monolitos/huancas) y como objeto de especialización del trabajo. A lo mencionado anteriormente, se complementa adicionalmente otros tres marcos para apreciar el antiguo trabajo en piedra: el tema de cultura visual como arte, siendo parte de objetos rituales del paisaje y dentro de la cultura arqueológica por sus rasgos funcionales y cronológicos.

El título del segundo capítulo, "Land of stones" ya va adelantando que el mayor interés en esta parte es el factor geológico/geográfico. Particularmente consideramos que no se ha puesto la atención debida a la relación del medio ambiente, específicamente en estudios paleoclimáticos, cuando se investiga en la zona de Ancash, en este caso del Callejón de Huaylas con las cordilleras Blanca y Negra. Cada cadena montańosa se caracteriza por elementos químicos y pétreos que lo hacen particular; así, tenemos en la zona oeste mayor abundancia de roca sedimentaria (caliza) y hacia el este, roca ígnea (granito) en su mayoría. Evidencia de esto se registran en los muros de varios sitios arqueológicos (La Galgada, Chupacoto, Hualcayán, Tumshukayko, etc.) hechos en piedra, lo que permite plantear tentativamente de donde ha sido extraído el tipo de material. Adicionalmente, la presencia del rio Santa marca diferentes pisos ecológicos que van desde los 2000 a 4500 m.s.n.m., siendo el único cuyas aguas van desde sur a norte en su trayectoria al océano pacifico, por lo que el autor resalta la importancia y potencial del diseńo natural en 
relación a la variabilidad geológica, las canteras y el transporte lítico.

En los casos de los capítulos 3 y 4, que abarcan una síntesis arqueológica de los periodos desde el Formativo Inicial hasta el Formativo Tardío-Final, el autor resalta la materialización del origen de la arquitectura monumental y la organización social que fueron reflejados materialmente con la Tradición Religiosa Kotosh, la cual se encuentra presenta en varios sitios de la sierra como La Galgada y Huaricoto, así como en la costa como por ejemplo en Caral, El Paraíso, Cerro Sechín, etc. Para el caso de análisis de Chavín de Huantar existen previos y numerosos trabajos que se centran en el arte lítico y la arquitectura de esta sociedad; sin embargo, Lau resalta el panteón lítico del sitio epónimo y su influencia en la región de Ancash. Seguidamente, capitulo 5, vemos que el autor hace énfasis sobre las diferencias marcadas (ya sea en arquitectura como escultura) que se dan después de lo conocido como "chavín", es decir el periodo de los diferentes grupos que el autor denomina como la mancomunidad recuay, Sitios como Janko, Yayno, Chinchawas y Pashash son algunos ejemplos citados, pero hay otros que son reportados a lo largo de Huaylas y Conchucos.

Seguidamente, al terminar la secuencia cronológica de Ancash, el autor toca estudios etnográficos en el siguiente capítulo. Primero, con respecto al tema Huari (representado por los mausoleos y tumbas en Honcopampa y Wilkawaín) e Inca (con su estilo en el trabajo con piedras en Yayno, Cajarumi y Huanuco Pampa), hay un mayor énfasis sobre estos grupos como parte de un colectivo mayor, lo cual se contrasta con las sociedades del Intermedio Tardío (por ejemplo, los sitios Huancajirca y Garu) con el estilo Aquilpo y la presencia de las huancas. Si bien tenemos un contexto de escasa información, este aproximamiento es importante pero limitado. Segundo, el capítulo 7 menciona el "antiguo juego andino" con los tableros hechos a piedra que estaría iniciándose con los recuay aparentemente. Esto se debe que Lau buscó abordar antiguas actividades sociales ${ }^{2}$ y su simbolismo con una cultura de oposición, basado en

2 En ese caso se podrían referir a relaciones de competencia, lo cual se registraría materialmente en varios ejemplares identificados en diferentes zonas. La lectura de estos se ordena mejor con el análisis estadístico de las dimensiones de los tableros y su comparación respectiva. comparaciones etnográficas con sociedades norte y mesoamericanas. Vale decir, según el autor, que no sería posible comprender la naturaleza de estos tableros como modelos arquitectónicos.

La penúltima parte, capítulo 8 , se diferencia en comparación con los demás ya que cuenta con un estudio antropológico sobre el empleo de la piedra en dos zonas especificas en Ancash. El primero es la zona norte de Pallasca ${ }^{3}$ y el segundo es en Huaraz. En el primer caso lo vemos en el distrito de Cabana y alrededores, como Huandoval y en el Museo Arqueológico de Cabana. En el segundo caso, dentro de los límites de la provincia de Huaraz, tenemos el Museo Arqueológico de Huaraz, con su parque lítico, y el sitio de Pumakayán. Vale decir que esta sección termina con un trabajo social ${ }^{4}$ que realizo el autor en los entornos donde estuvo con las personas que aún trabajan con la piedra en el ámbito de la construcción, artesanía, etc. Por ejemplo, el caso de reproducción de la técnica de la huanca pachilla en algunas casas contemporáneas es notaria y también el caso de réplicas para vender como recuerdos o regalos. En otras palabras, hay un mayor interés en la arqueología como modelo para la aplicación del marketing, turismo, política, etc. lo cual se ve reflejado en la siguiente oración:

More than any other medium in Ancash's past, stone embodies the imagination of the past and actualizes benefits for the present. ${ }^{5}$ (pág. 209)

Por último, Lau termina haciendo como síntesis del libro en dos páginas al señalar que, a diferencia de los análisis de los materiales de cerámica y textiles, los estudios del soporte lítico deben ser considerados más a menudo en los procesos de investigación, especialmente porque dado a su naturaleza, se puede hacer un seguimiento de la duración del material. Además, estos pueden formar parte dentro del análisis etnográfico ya que nos puede dar ideas sobre la

3 Vale decir que esta zona es conocida por el autor en los años de investigación para entender más sobre los Recuay y su subdivisión en el norte.

4 Hay que resaltar el esfuerzo por explicar la secuencia de tallado-técnica que se ve reflejado en la figura 8.12, donde el objetivo del autor es entender que entre las imágenes de guerreros recuay, cabezas clavas y lanzones, hay una aceptación de identidad.

5 "Más que cualquier otro medio en el pasado de Ancash, la piedra encarna la imaginación del pasado y actualiza los beneficios para el presente." (la traducción es nuestra). 
identidad de la comunidad con su relación secularsagrado y/o el uso que tenía y donde se usaba. Esto resulta muy importante ya que el autor resalta que las piedras antiguas siguen siendo agentes activos dentro de la mentalidad del colectivo popular en los Andes y específicamente en Ancash. Al final, Lau reconoce que, si bien este volumen es un análisis parcial por enfocarse en un solo elemento; cuando se trata de la prehistoria, todos los análisis son parciales.

En resumen, hay pocos trabajos presentados desde un enfoque holístico y que a la vez profundice seriamente sobre un soporte material en específico, para este caso la piedra. Esto nos hace reflexionar que hoy en día, entre investigadores de la comunidad arqueológica, no es usual observar la publicación de libros, esto en comparación con la publicación de artículos o compilaciones hechas por editores. Razones para esto varían, desde una carencia de tiempo por parte de los autores hasta una ausencia de continuidad en las investigaciones que se plantean y que por tanto solo ameritan pequeños artículos. Es por esto que es grato examinar un volumen coherente que presenta una sobresaliente síntesis de varios años de estudio por parte de Lau en una zona en específico. Así, la presente publicación es el resultado del esfuerzo del autor por entender la arqueología del área norcentral por medio del análisis de las evidencias líticas específicamente y del tipo de trabajo a este soporte per se.

José Samuel Querevalú Ulloa Universidad Nacional Mayor de San Marcos sam23qu@hotmail.com 